\title{
A construção da identidade de jovens negros do Palmital
}

Moisés Ferreira Geraldo*

\begin{abstract}
Resumo
A juventude negra enfrenta atualmente um grande desafio nas áreas periféricas. Alvo principal da violência urbana tem na cor da pele a marca de uma exclusão histórica como desafio de sobrevivência. Os números de vítimas da violência é uma das expressões da desigualdade que afeta essa população. O artigo tem como proposta abordar a juventude negra e suas estratégias para construção da identidade étnicoracial no conjunto habitacional Palmital localizado na periferia da cidade de Santa Luzia, região metropolitana de Belo Horizonte.
\end{abstract}

Palavras-chave: Juventude - identidade - Relações étnico-raciais

\section{Introdução}

A juventude negra enfrenta, atualmente, um grande desafio nas áreas periféricas. Alvo principal da violência urbana tem na cor da pele a marca de uma exclusão histórica como desafio para a sobrevivência. $O$ número de vítimas da violência é uma das expressões da desigualdade que afeta essa população. A partir dessas afirmações, este artigo tem como proposta caracterizar a juventude negra, abordando suas estratégias para construção de uma identidade étnico-racial no conjunto habitacional Palmital, localizado na periferia da cidade de Santa Luzia, região metropolitana de Belo Horizonte. Na primeira parte, discorre-se sobre a história Palmital buscando resgatar o processo de instalação do conjunto na região e os seus impactos na experiência juvenil. A segunda parte discute a questão que envolve o que é ser jovem e negro no Palmital, mostrando as estratégias utilizadas por uma juventude que enfrenta, pela origem e pelo contexto atual do bairro, barreiras para seu desenvolvimento. Parte-se da perspectiva de que a construção da identidade negra está intimamente relacionada ao enfrentamento desses problemas.

\section{Um breve histórico do Conjunto Habitacional Palmital}

Revista @rquivo Brasileiro de Educação, Belo Horizonte, vol.2, num.3, jan - jun, 2014
* Mestrando da Faculdade de Educação - FAE/UFMG - vinculado ao grupo de pesquisa Observatório da Juventude/UFMG e orientado pelo Prof. Dr. Geraldo Magela Pereira Leão. 
O conjunto habitacional Palmital, localizado na cidade de Santa Luzia, região metropolitana de Belo Horizonte, se caracteriza por ter uma população com perfil socioeconômico baixo e que, pela forma de sua ocupação, apresenta uma história de exclusão social e de luta pelo direito a uma moradia digna. Ele é resultado de uma política nacional de habitação, implantada pelo governo federal, na década de 1960, em parceria com os governos Estaduais e Municipais, implantada em várias regiões do Brasil e, principalmente, nas áreas metropolitanas, buscando alocar populações de baixa renda a uma moradia.

O conjunto habitacional Palmital foi construído pela Companhia de Habitação de Minas Gerais (Cohab-MG), criada pelo governo em 1965, com a finalidade de combater o déficit habitacional e urbanizar vilas e favelas no Estado. Essa política habitacional era financiada pelo Banco Nacional de Habitação (BNH), criado em 1964. O BNH era responsável pela produção e financiamento de empreendimentos imobiliários. Sua atuação era indireta, por meio de bancos públicos e/ou privados e de outros agentes, tais como as companhias habitacionais e as companhias de água e esgoto. A Cohab-MG inicia seus trabalhos, em 1967, com a construção do conjunto habitacional Jatobá, localizado em Belo Horizonte, intensificando, nesse período, uma política de expansão habitacional para região metropolitana. Essa política habitacional gerou um aumento populacional nas cidades do entorno da capital. Segundo o Instituto Brasileiro de Geografia e Estatística (IBGE), no período de 1980 a 2010, os números revelaram que as populações dos municípios vizinhos aumentaram consideravelmente. Um exemplo é Santa Luzia que, de uma população de 59.892, em 1980, saltou para 202.942, em 2010.

A construção do conjunto habitacional Palmital e do conjunto habitacional Cristina, na mesma região, foi responsável pelo aumento populacional do município de Santa Luzia na década de 1980, principalmente no distrito do São Benedito, onde a política habitacional foi concretizada. O Palmital faz limite com o conjunto habitacional Cristina e com os bairros São Cosme e Três Corações. Localiza-se entre três vilas ou aglomerados: a Vila das Antenas, uma ocupação que se fixou em uma área abaixo das antenas de transmissão de energia da CEMIG e que concentra grande parte de ex-moradores do conjunto habitacional; a Vila Nova Conquista que surgiu de uma área verde que era utilizada como pasto para animais e que foi ocupada por famílias 
de diversas localidades, tanto de Belo Horizonte e de cidades da região metropolitana como também do próprio conjunto habitacional; e, por último, a Vila Nova Esperança, uma área verde, ocupada em 1991, por famílias oriundas do bairro São Cosme e por ex-moradores do Palmital. Essas áreas compõem um cinturão de pobreza e desigualdade social.

Os moradores do conjunto Palmital são, em sua maioria, oriundos de vilas e favelas de Belo Horizonte, que ocupavam áreas de risco. Após as fortes chuvas ocorridas no ano de 1983, milhares de famílias se viram na situação de ter de abandonar de suas casas, devido à condição iminente de desabamento. Áreas ao redor dos córregos do Nado, Leitão, Ribeirão do Onça e do rio Arrudas foram as mais atingidas pelas águas. Os moradores foram direcionados para abrigos municipais e, posteriormente, para conjuntos habitacionais, num caráter de urgência. Já os moradores das favelas de Santa Tereza, União, Belém, São Rafael e Caetano Furquim tiveram como destino o conjunto Palmital. Esse processo de remoção de áreas de risco foi pautado por tensões entre a prefeitura e as famílias. O poder público queria direcionar esse grupo para região metropolitana fora do limite do município, mas famílias exigiam a permanência na região onde viviam há anos. Essa situação se transformou em uma luta de resistência, pois os moradores acreditavam que a permanência no local de origem era um direito.

$\mathrm{Na}$ inauguração, o Palmital encontrava-se em uma situação precária, sendo alvo de reclamações dos novos habitantes, uma vez que faltava o mínimo de estrutura. A constante falta de energia elétrica e de água obrigava o uso de velas ou lamparinas e à utilização da água de uma mina conhecida como "biquinha". A ausência de comércio no local forçava a população a andar longos trechos até o São Benedito, onde havia o único ponto de comércio da região. Não havia escolas, posto de saúde e nem posto policial. As crianças e os jovens em idade escolar tinham que caminhar longos trechos para frequentarem instituições de ensino fora do bairro e, caso ocorresse alguma urgência médica, as famílias tinham que recorrer ao serviço de saúde pública de Belo Horizonte. Em relação ao transporte, o bairro não contava com esse serviço, sendo implantado somente dois anos após sua inauguração. Muitas famílias não suportaram tais situações e abandonaram a região retornando a Belo Horizonte. Venderam as casas a preços irrisórios ou saíram delas e se instalaram nas áreas verdes e comunitárias do bairro, 
iniciando ocupações no entorno do conjunto. Observam-se, assim, alguns elementos que contribuíram para a sedimentação de um estigma negativo para o bairro, como a origem dos moradores de favelas da capital, aliada à situação precária do local e à ausência de serviços básicos, como infraestrutura urbana e transporte.

Com o passar do tempo, os problemas foram se agravando e os moradores do Palmital se viram isolados numa região desconhecida e distante de toda uma rotina construída em torno do trabalho, da escola, do comércio, etc. Mesmo vivendo em uma realidade difícil nos locais anteriores de moradia, eles se viam melhores quando residiam em Belo Horizonte. As dificuldades enfrentadas no cotidiano direcionavam os moradores para duas alternativas: mudar-se para outro lugar com estrutura mais sólida ou permanecerem ali e buscarem soluções partindo de ações coletivas. Como muitas famílias não tinham condições de se mudar, a solução foi permanecerem no local e se mobilizarem para um processo de mudança no bairro.

\section{Ser morador do Palmital}

A herança de uma história de luta das famílias por moradia veio a fortalecer as relações estabelecidas entre os moradores do Palmital, pois muitos relataram que a vida na favela, apesar de todos os problemas, era melhor do que a vida que eles estavam vivendo. As melhorias começaram a ocorrer a partir do momento em que a população mobilizou-se e formou a primeira associação comunitária, a ASCOPA (Associação Comunitária do Palmital), no ano de 1984. O conjunto habitacional foi se estruturando através da pressão e reivindicação da população que não acreditava no poder público como aquele que iria resolver seus problemas. O sentimento de isolamento e segregação resultou em aspectos negativos para seus moradores, mas também gerou uma força contrária que se depositou nas mobilizações capazes de promover avanços na organização comunitária e nas melhorias futuras.

Partindo das mobilizações, o problema da energia elétrica e do abastecimento de água foi regularizado, permanecendo, ainda, o problema nas áreas de aglomerados no entorno. $O$ restabelecimento do transporte coletivo foi uma conquista marcante para os moradores. Mesmo com os problemas que esse serviço apresenta no seu cotidiano, não só no Palmital, mas de uma forma geral, trouxe uma mobilidade até 
então inexistente. A construção de escolas estaduais e municipais, do posto de saúde, do pelotão da Polícia Militar e da delegacia da Polícia Civil configuraram outras conquistas. Atualmente, o bairro abriga A.I.S.P, Áreas Integradas de Segurança Pública (2003), cujo objetivo de integrar no mesmo espaço a Polícia Militar e a Polícia Civil.

A história do Palmital e de suas famílias é um elemento importante para entendermos a estrutura social que se construiu no decorrer dos anos de 1984 a 2013 numa pluralidade de origens. Como a dinâmica de pertencimento foi construída entre seus moradores através de diversos problemas enfrentados? Como identificar os mecanismos que levam à superação desses problemas?

\section{O Palmital além dos problemas}

O Palmital traz, na sua história, um conjunto de experiências acumuladas e de estratégias de superação dos problemas, no qual sua população heterogênea, na medida em que as origens das famílias são de locais diferentes, construiu uma coletividade atendendo uma lógica própria de identificação e pertencimento ao local de morada. A segregação residencial imposta a esse grupo é uma marca presente na construção da identidade dos moradores de áreas periféricas que são categorizadas, pelo poder público e pela sociedade, como áreas de vulnerabilidade social. A construção do reconhecimento como cidadão de uma cidade e de um bairro acontece nas identidades encontradas e nos exemplos que vão surgindo que se tornam referências para a luta por dignidade e respeito, através de uma mobilização paralela ao poder público.

Conhecida como uma localidade violenta, registrando altos índices de homicídios entre o grupo jovem, relacionados diretamente com o tráfico de drogas, o bairro apresenta um quadro que aumenta o preconceito para com os moradores. A população jovem, em especial, é estigmatizada de forma negativa por morar em uma localidade marcada também pela de desigualdade e pela pobreza. Ser jovem e morador do Palmital traz um desafio maior: o de romper, cotidianamente, com uma lógica cruel de discriminação. Inverter essa lógica num sentido próprio de viver é ir para além das barreiras impostas e identificar, nos problemas do bairro, estratégias de enfrentamento, buscando pensar soluções coletivas. Diagnosticar, na história do Palmital e nas suas 
memórias coletivas elementos para a construção de uma identidade que fortaleça o sentimento de pertença, partindo do resgate das narrativas de experiências, constrói também a riqueza cultural do bairro.

As experiências acumuladas nos leva a perceber os caminhos possíveis que podem ser traçados em uma localidade marcada pela desigualdade, condição de pobreza e marginalidade que, infelizmente, é real.

O resgate da história do bairro e de seus moradores é o desafio de hoje, buscando narrativas de vidas que retratem o cotidiano, partindo da história local numa perspectiva em que o sujeito que narra se vê como sujeito que constrói.

\section{Impactos na experiência juvenil do bairro}

O jovem se socializa na realidade do Palmital e encontra nesse contexto barreiras para seu reconhecimento efetivo como sujeito de direitos pelas instituições que os cercam. Visto como problema, carrega na sua trajetória, o peso da intervenção dos adultos nas suas perspectivas e decisões. Dificulta-se a essa juventude o acesso a políticas públicas capazes de garantir a fruição de bens materiais, culturais e políticos, sendo limitadas as iniciativas visando à criação de espaços públicos que privilegiem a sociabilidade. Para Abramo (1997) as questões elencadas são sempre aquelas que constituem os jovens como problemas para si próprios e para a sociedade, isto é, sua condição de juventude é pensada na lógica do adulto, por isso se compreende que esse momento é propício para o erro.

As propostas de diálogo impostas aos jovens, seja pelo poder público ou sociedade civil, sempre envereda pelo discurso do moralismo, enquadrando-os a um modelo de consumo sem limite e desconectados da lógica de trabalho, isto é, há uma clara associação à "preguiça" e à falta de interesse. Deposita-se no jovem a perda de valores comunitários, levando a um raciocínio de que ele não se importa com os problemas enfrentados pelo seu bairro ou pela cidade. Porém, o que mais impacta a juventude é, certamente, o estereótipo da agressividade como algo inerente a sua natureza, justificando, desse modo, práticas de repressão social sobre eles. Cria-se, portanto, uma dimensão que nos leva a pensar que os jovens estão alheios ao mundo que o rodeia e não são capazes de enfrentar sozinhos os problemas. 
A juventude, na realidade, nos mostra outro quadro de representação, uma lógica própria de experimentar a vida que, por muitas vezes, se confronta com o mundo dos adultos na medida em que estão inseridos nas mesmas regras e normas, mas que se posicionam de maneiras diferentes. O jovem morador de periferia convive com estereótipos negativos que acabam superando suas potencialidades e reduzindo-os a uma análise que parte da realidade social e do lugar onde vivem numa perspectiva de limite. O que se observa, porém, é que a juventude interage com os problemas do bairro e tem a consciência de sua dimensão, apresenta uma identidade pautada no campo das "resistências", isto é, através do seu discurso, modo de vestir, de falar e de agir que são próprios do seu tempo de vivência e demonstram elementos reveladores de uma cultura urbana.

A construção de uma identidade não é um exercício simples que se inicia de dentro para fora somente num exercício isolado. Pelo contrario, é, na verdade, uma relação de experiência com outro, isto é, eu construo meu significado partindo da interação com o grupo ao qual pertenço. É uma relação permeada de tensão entre o mundo interior e exterior. Para Bauman:

[...] Tornamo-nos conscientes de que o "pertencimento" e a "identidade" não têm a solidez de uma rocha, não são garantidos para toda a vida, são bastante negociáveis e revogáveis, e de que as decisões que o próprio indivíduo toma, os caminhos que percorre, a maneira como age - e a determinação de se manter firme a tudo isso - são fatores cruciais tanto para o "pertencimento" quanto para a "identidade". (BAUMAN, 2005, p.17).

O autor defende que experimentamos uma identidade líquidomoderna, um contexto que o mundo vive hoje, uma fragmentação dos ritmos que recai sobre o sentido da nossa existência. Permeada por sucessões de episódios ligadas por conexões frágeis, às relações passam, portanto, a serem efêmeras, num processo constante de mudança na nossa identidade.

O exercício da construção de uma identidade faz com que os jovens do Palmital adotem posturas diferenciadas conforme o lugar de vivência. Quando o contexto traz algum benefício, a postura é assumir, de forma ativa, a identidade de morador do bairro como meio de intimidar, utilizando o perfil de violência como estratégia, mas quando a situação 
de assumir onde mora não traz benefício algum, a postura é negar e dizer que mora em algum bairro vizinho. Essa situação demonstra que a identidade utiliza elementos de estratégia e negociação.

As estratégias adotadas para negar a identidade com o bairro em locais como lojas, shopping, bares, eventos e oportunidades de emprego, consistem em romper ou neutralizar qualquer elemento que possa identificar o jovem como morador de uma área de vulnerabilidade social. Pensar o local de origem na perspectiva da negação resulta numa dimensão imaginária negativa do espaço e das pessoas que ocupam essa localidade.

Castell (1999) nos traz uma discussão importante sobre identidade partindo do campo da "resistência" no qual o marginalizado busca caminhos alternativos para confrontar o poder estabelecido pelas instituições sociais. Para o autor:

[...] identidade de resistência: Criada por atores que
se encontram em posições/ condições desvalorizadas
e/ou estigmatizadas pela lógica da dominação,
construindo, assim, trincheiras de resistência e
sobrevivência com base em princípios diferentes dos
que permeiam as instituições da sociedade, ou mesmo
opostos a estes últimos [...]. (CASTELL, 1999, p.24).

Negar-se ou afirmar-se como morador do Palmital é uma forma de construir identidades (no plural) atendendo a uma lógica flexível e negociável, contrapondo a uma rigidez na construção da identidade. Para Hall (2011), as identidades não são fixas, são representadas através do debate com os sistemas culturais no qual estamos inseridos, isto é, sistemas de significação e representações culturais, numa perspectiva de identidades possíveis.

É um desafio para a juventude do Palmital enfrentar a pobreza e a desigualdade, que se transformam em barreiras para o seu desenvolvimento. Podemos entender esses desafios através das estratégias adotadas para escapar da violência do tráfico de drogas, do Estado, da evasão escolar, dos subempregos para se manter vivo. Ser jovem, no Palmital, passa pela luta cotidiana em se manter preservado das múltiplas formas de violência e buscar forças para ir além das barreiras impostas à sua condição de juventude.

A segregação urbana como fator de manutenção de exclusão 
dos jovens utiliza, nesse caso, o critério da pobreza. O Palmital nasceu, portanto, de uma política habitacional que atenderia a uma lógica de alocar populações com perfis socioeconômicos homogêneos, isto é, manter historicamente uma condição de distanciamento do seu território para reforçar as diferenças entre os grupos sociais. A condição de marginalidade imposta à periferia tem como base a lacuna existente entre ricos e pobres. Nesse caso, o espaço apresenta-se como elemento de exclusão. De acordo com Lefebvre:

[...] Excluir do urbano grupos, classes, indivíduos, implica também excluí-los da civilização, até mesmo da sociedade. O direito à cidade legitima a recusa de se deixar afastar da realidade urbana por uma organização discriminatória, segregadora. [...] centros de decisão, de riqueza, de poder, de informação, de conhecimento, que lançam para os espaços periféricos todos os que não participam dos privilégios políticos. (LEFEBVRE, 2008, p. 32).

A construção da identidade negra para muitos jovens do Palmital está vinculada à experiência da desigualdade e a luta pelo direito à cidade de que nos fala o autor.

\section{Ser jovem negro no Palmital}

Podemos começar discutindo sobre a identidade negra, cuja construção é pautada na interação. Assim, o conceito identidade passa pela concepção que o indivíduo faz de si mesmo, intermediada pelo reconhecimento do outro. Constituída na interação, resulta, portanto, em uma negociação ou diálogo dos elementos interiores com os elementos exteriores. Esses processos são tensos e complexos na medida em que a identidade negra vem sendo ressignificada, historicamente, desde período da escravidão até as formas atuais veladas de racismo, alimentada pelo mito da democracia racial e, ao mesmo tempo, contraposta pelas lutas de resistências negras experimentadas na história do Brasil.

Atualmente, a sociedade brasileira e o poder público tem o desafio de promover o combate ao racismo como um dos eixos centrais de uma nova agenda de debates que contemplem a promoção à diversidade racial. Esse combate ao racismo e a discriminação racial, constituem ações importantes para dar outro significado à história do negro, modificando também a estrutura social de desigualdade que o país apresenta. 0 modelo adotado no Brasil em relação à história do negro reforça um estigma de inferioridade em relação ao branco. 
A herança africana é muito forte na nossa história, estando o país na segunda colocação como maior nação negra do mundo. O Brasil só perde para a Nigéria, que fica no continente africano. Os milhões de negros e negras estão mais conscientes de suas origens. Com a implantação e implementação da lei 10.639/03 que tornou obrigatório o ensino da História da África e Culturas Afro-brasileiras na educação básica e dos sistemas de cotas raciais nas universidades brasileiras, houve um fortalecendo de um movimento de reconhecimento da contribuição do negro para a história e para a identidade brasileira. Mas, lamentavelmente, persiste ainda sobre a população negra uma herança histórica de três séculos de escravidão e de um longo período de racismo velado permeado por uma invisibilidade social. Negado nas nossas relações a existência do racismo traduz-se no preconceito, discriminação e exclusão social.

As condições de marginalidade e exclusão social em que vive grande parcela da população negra requerem da sociedade civil e do poder público uma urgência de políticas públicas voltadas para esse segmento. A pobreza no Brasil tem a cor negra, e tem endereço, as periferias e favelas. Podemos, então, concluir que nem todos os pobres do Brasil são negros, mas é fato que a grande maioria dos negros no Brasil é pobre. O jovem negro do Palmital se apresenta como grupo frágil nesse contexto, pois carrega os estereótipos de ser negro, jovem e pobre numa localidade que sofre o peso da discriminação, desde a sua origem.

No que tange à juventude, o mundo vive hoje um momento especial, pois nunca teve tantas pessoas numa faixa etária entre 15 a 29 anos. Em 2010, 26\% da população mundial era jovem. No Brasil, 26\% da população estava na faixa etária entre 15 a 29, anos representando 51 milhões de um total de 200 milhões, segundo o Instituto Brasileiro de Geografia e Estatística (IBGE). Quando separamos os dados por cor ou raça os números passam a ser mais significativos. Dos $26 \%$ de jovens no Brasil, 53,59\% se declararam negros (27.514.695 milhões). A juventude negra se faz presente nessa faixa etária sendo merecedora de uma atenção especial. Ao se declarar espontaneamente como negro, percebemos uma mudança no cenário étnico-racial no qual podemos citar como influência os efeitos da lei 10.639/03 e dos sistemas de cotas.

Já em Santa Luzia, segundo dados do IBGE de 2010, 73\% da 
população se declarou negra (145.366). Do total da população, 36,7\% (55.270) são jovens entre 15 e 29 anos, dos quais, aproximadamente $70 \%$, são negros (pretos e pardos). A população jovem de Santa Luzia pertencente à etnia negra é significativa nessa faixa etária. Os números mostram a urgência por parte do poder público na elaboração de políticas públicas que atendam à necessidade dessa parcela da população. Verificase, dessa maneira, que a população negra se faz presente como a maioria, mas no campo da representatividade, encabeça uma estatística negativa no cenário brasileiro. Estudos da Secretária de Políticas de Promoção da Igualdade Racial (SEPPIR) mostram que, em 2010, 54\% da população se declarou negra (96,7 milhões). Entretanto, comparando a participação do negro em alguns setores, percebemos a exclusão de forma efetiva. Segundo a Pesquisa Nacional por Amostra de Domicílios (PNAD) de 2008, 10\% da população brasileira com mais de 15 anos é composta por analfabetos. Nesse grupo, a taxa de analfabetismo da população negra era, proporcionalmente, $118,4 \%$ superior a dos brancos. No mapa da violência, A cor dos homicídios no Brasil, lançado em 2012, nos mostra o lado cruel do racismo brasileiro. A taxa de homicídios por cor ou raça, numa comparação no período de 2002 a 2010, chega aos seguintes resultados: entre os brancos a taxa de homicídio, em 2002, era de $41 \%$ e, em 2010, de 24,6\%, evidenciando uma redução na taxa de homicídios para a população branca. Para a população negra, a taxa em 2002 era de $58 \%$ e, em 2010, passou para 71\%, revelando um expressivo aumento. Quando essa taxa de homicídios é direcionada ao jovem, os números são alarmantes. Os brancos chegavam em 2002 a 37,5\% e, em 2010, passou para $24,6 \%$ e enquanto os negros em 2002 a taxa era de $62,2 \%$ e para 2010 foi para 75,1\%. Podemos concluir, sem medo de errar, que a população jovem negra está sendo exterminada como em um cenário de guerra.

Justifica, portanto, buscar esse grupo étnico como objeto de estudo, pois como a maioria da população de Santa Luzia é negra essa estatística se confirma no Palmital. A violência, a evasão escolar, a ausência do mercado de trabalho e o racismo são elementos desafiadores para a juventude negra que carrega o peso dessa realidade.

A experiência de ser negro e morador do Palmital acarreta para essa juventude uma vivência própria, pois eles estão cotidianamente expostos aos problemas do bairro. Essa experiência revela uma necessidade de um olhar crítico sobre a própria história de vida, 
identificando na particularidade do local, as articulações de elementos que levam a afirmação e ao reconhecimento da condição de negro, buscando captar os elementos para uma reflexão que permitam compreender o pertencimento. A construção da identidade étnico-racial se dá nos múltiplos espaços onde esse jovem se inseriu, a família, escola, programas sociais, coletivos de jovens ou qualquer espaço apropriado por essa juventude. Espaços que aproximam as histórias de vida de uma juventude que tem em comum o lugar onde mora e a cultura negra, buscando na experiência do outro um campo de possibilidades e estratégias. A partir dessa interação, vai-se desenvolvendo um modo de ser, um estilo de vida e estratégias que fortalecem a identidade com a cultura negra. Essa é nova dimensão para a juventude negra, que reconhece, no contexto social, novas possibilidades que privilegiam a interação com a comunidade e que rompe cotidianamente com a lógica do limite, do racismo e da discriminação.

Diante de um contexto social excludente, que tem nas suas principais vítimas o segmento juvenil negro é possível, encontrarmos um poder de mobilização em seus diversos formatos socioculturais que adotam o hip hop, os blocos afro e outros coletivos de estudantes negros como forma de fortalecer a identidade negra. Muitos desses coletivos não têm como objetivo explícito a discussão sobre a identidade negra, mas a sociabilidade, a troca de experiência e o exercício da escuta contempla o debate sobre ser jovem negro no Palmital.

Há que se ressaltar, ainda, o poder de apropriação e resignificação que esses jovens negros dão aos espaços frequentados, em confronto com a ótica adulta. $O$ boné virado de lado, mas que não atrapalha o penteado, as roupas largas deixando à mostra a peça íntima que faz parte do conjunto, o fone de ouvido ou as caixinhas de som, como peça fundamental junto ou não de um skate ou o tom preto das vestimentas são traços que marcam o modo ser desses jovens. O rap, o hip hop, o funk, o rock ou o axé embalam suas rodas de conversas e danças e seus jeitos despojados e naturais, jogando baralho, soltando papagaio ou jogando bola ou basquete. Essas dimensões são múltiplas e não cabe neste momento mapea-las, mas mostrar uma dinâmica juvenil própria, aquela que ocupa o seu espaço. Na praça chamada de "Savassinha", situada no centro do bairro, essas relações acontecem, seja numa reunião dos jovens evangélicos para escutar e cantar rap ou um grupo que vai jogar 
basquete ou falar de futebol. É aí também o espaço da transgressão, pois os jovens que o ocupam para fazerem uso de drogas e bebidas. Evidencia-se, assim, a noção de espaço da permissão.

A rua também ganha esse significado de sociabilidade e educação, o bate papo nas esquinas, no campinho no final da rua e até mesmo entorno das bocas de fumo. A significação que a juventude dá ao lugar onde mora atende a uma lógica própria de como se ver diante dos espaços institucionalizados. Durante o dia, é permitido frequentar e transitar livremente, mas, conforme a hora, aquele espaço perde esse sentido inicial, passando a ser um lugar de transgressão. Os espaços ganham um sentido fluído, assim como as identidades de quem os frequenta. Há uma variabilidade do sentido da apropriação. Durante o dia, crianças, jovens e idosos se apropriam do local. A ociosidade e o lazer ganham aspectos positivos, mas, durante a noite, ele é frequentado por traficantes e viciados para venda e consumo de drogas. Nesse momento ganha um aspecto negativo e perigoso. A rua toma essa mesma dimensão e a vigilância da própria polícia atua nessa variabilidade do sentido do espaço. O jovem imerso a essa dimensão busca confrontar os estereótipos atribuídos a esses espaços, tendo uma percepção diferente do adulto no que se refere à possibilidade de ocupa-los.

A identidade é um instrumento importante para o alargamento da condição de ser jovem no Palmital. A todo o momento ele é chamado para essa discussão sobre sua identidade como morador de uma área violenta e vulnerável e pela experiência do racismo. A necessidade de trabalho é muito grande e ganha relevo, dessa forma, a decisão entre completar os estudos e trabalhar e ganhar dinheiro para ajudar em casa ou inserir-se ao mundo do consumo. Esse é um dos dilemas comuns para essa juventude periférica. Muitos abandonam a escola para assumir empregos temporários ou no caráter informal. Outros percebem a dificuldade de inserção no mercado de trabalho pela falta da escolaridade. O mercado de trabalho passa a ser um desafio para esse jovem, pois ele precisa superar o problema da segregação residencial, da formação deficiente e do racismo.

Os jovens negros acabam exercendo sua identidade de forma negociada, nas experiências fora do bairro, por exemplo, quando vão participar de uma entrevista de emprego. Assumir a negritude através do cabelo, das roupas e até mesmo no discurso é um elemento 
desfavorável para inserção nesse mercado. Muitos deles não trançam os cabelos ou usam penteado que ressaltam a suas características raciais, mesmo achando bonito, por causa da rejeição das pessoas a esse tipo de manifestação. Por isso, é muito comum, durante finais de semana ou feriados, aproveitarem a oportunidade de expressar a cultura negra através dos penteados, das roupas e da fala, pois estão no seu espaço, e, durante a semana, no trabalho, tendem a ocultar essa postura por medo de sofrerem alguma forma de preconceito.

No imaginário dos moradores do Palmital paira uma realidade que é a construção de uma referência. É muito comum termos como exemplo pessoas que se destacam através dos estudos ou no trabalho, terem a tendência a se mudarem para oura localidade. Cria-se no imaginário, e no desejo íntimo, um sentimento de sucesso atrelado à fuga da região. É muito comum ouvirmos dizer que "fulano se deu bem na vida e foi embora daqui, também aqui é lugar de gente morar?" Muitos pais matriculam seus filhos em escolas fora do bairro por achar que a convivência com outras pessoas fora daquele contexto irá trazer benefícios futuros.

Como a população, de modo geral, trabalha em Belo Horizonte, acaba tendo uma vida social ligada a capital. O bairro passa ser um lugar dormitório, pois a vida das pessoas é fora dele. Essa lógica, portanto, permeia o imaginário da juventude local, pois tudo que passa a ser referência está fora de lá. Muitos jovens tem vergonha de dizer onde mora porque dentro do próprio bairro existe uma discriminação. Por exemplo, quem mora no setor 7 localizado no Palmital A, área conhecida na região como "caldeirão dos infernos", é discriminado por causa da pobreza e do alto índice de crimes relacionados ao tráfico de drogas. Muitos jovens perdem a vida pela guerra do tráfico de drogas entre grupos rivais. Passam a ser "aviãozinhos" isto é, comercializam a droga para o traficante e usam armas no local onde moram. As meninas são cooptadas por uma rede de prostituição e abuso sexual que, na maioria das vezes, atende o próprio tráfico. A realidade vivida por essa juventude é cruel. O crime organizado tem nesse grupo uma "massa de reserva" da qual se utiliza, tanto pela fragilidade das famílias quanto pela ausência do Estado, recrutando esses jovens com falsas promessas e acesso facilitado ao mundo do consumo.

O Conjunto habitacional Palmital não está desconectado da 
cidade de Santa Luzia e nem do restante da capital. Os significados e as relações que acontecem em espaços fora do bairro contribuem para um fortalecimento ou enfraquecimento da identidade e do pertencimento étnico. Entendemos que as trocas acontecem entre o sujeito e o lugar, havendo compartilhamentos de experiências no e do lugar. Para o jovem negro, morar no Palmital é ampliar os significados das ruas, praças, pontos de encontro, lugares de trabalho e diversão, de paisagem, de sociabilidade e de identidade.

\section{Conclusão}

A política habitacional implantada pela Cohab-MG, na região metropolitana de Belo Horizonte, simbolizou um processo de exclusão de uma parcela da população pobre. Aglutinar em uma mesma região todas as famílias pobres de diferentes áreas metropolitanas e da própria capital gerou um fenômeno conhecido como segregação residencial. A marginalização dessa população atendeu uma lógica de ações de remoção de um perfil populacional ocupante de áreas nobres de Belo Horizonte, mas no entendimento do poder legitimado, esses cidadãos não eram dignos de habitarem tais áreas. Percebe-se com essa estratégia de deslocamento populacional, uma clara política de especulação imobiliária que tem como princípio básico o lucro.

O conjunto habitacional Palmital é resultado dessa política de moradia que alocou famílias de favelas de Belo Horizonte. Os problemas enfrentados pelos moradores do bairro gera uma situação de desigualdade e violência. Desde sua origem até os dias atuais, os seus moradores precisam enfrentar uma luta para se reafirmar cotidianamente como moradores de uma área vulnerável socialmente. A busca por dignidade, pelo rompimento do preconceito e dos estigmas negativos que pesam sobre a imagem de si mesmo, é constante. A juventude, pensada no campo das possibilidades, ganha visibilidade em meio a tanta violência na medida em que demonstra estratégias de superação e de resgate de uma identidade de pertencimento ao lugar onde habita, possibilitando uma dimensão de socialização e autonomia.

Se afirmar como negro, apesar de todas as dificuldades entorno das questões raciais no Brasil passa ser um instrumento importante para o fortalecimento da identidade desse segmento. A juventude negra, imersa a um cenário de extermínio na sociedade brasileira, busca 
estratégias de sobrevivência através da consolidação da sua identidade negra, através das múltiplas manifestações que possam fortalecer sua etnia. O Palmital passa ser o espaço dessa construção identitária. Se por um lado temos um quadro de desigualdade, violência e racismo, por outro, temos uma realidade de resistência se fortalecendo que se verifica cotidianamente.

\begin{abstract}
Today, the black youth faces a major challenge in suburban areas. As a main target of urban violence, their skin color is the mark of a historical exclusion through the survival process. The number of victims of violence is one of the expressions of the inequality that affects this population. This article aims to comprehend the black youth and its strategies to build their ethnic-racial identity in the public housing of Palmital, located in the suburbs of the city of Santa Luzia, in the metropolitan area of Belo Horizonte.
\end{abstract}

Keywords: Youth. Identity. Ethnic-racial relations.

\title{
Referências
}

ABRAMO, Helena Wendel. Considerações sobre a tematização social da juventude no Brasil. Rev. Bras. Educ. [online]. 1997, n.05-06, pp. 25-36.

BAUMAN, Zygmunt. Identidade: entrevista a Benedetto Vecchi. Rio de Janeiro: Zahar, 2005. P.109.

CASTELL, Manuel. 0 poder da identidade, v. 2. São Paulo: Paz e Terra, 1999.

GOVERNO FEDERAL. Secretaria de Políticas de Promoção de Promoção da Igualdade Racial - SEPPIR. Perspectivas Negras - Construindo políticas públicas na intersecção entre Juventude e Promoção da Igualdade Racial. Relatório. Brasília, 2011.

HALL, Stuart. A identidade cultural na pós-modernidade. Trad. Tomaz Tadeu da Silva e Guacira Lopes Louro. 11.ed.. Rio de Janeiro: DP\&A, 2011.

IBGE - Instituto Brasileiro Geografia Estatístico. Censo Demográfico. Rio de Janeiro: IBGE, 2010.

LEFEBVRE, Henri. Espaço e política. Belo Horizonte: Editora UFMG, $2008,192 \mathrm{p}$. 